\title{
Magnolia Champaca- Flower Extracts As Corrosion Inhibitor For Mild Steel In Acid Medium
}

\author{
S.Ananth Kumar, A.Sankar*, M.Vijayan, S.Rameshkumar \\ ${ }^{a}$ Kandaswami Kandar's College, P. Velur, Namakkal-638 182, India \\ ${ }^{b}$ Scientist ,centre for conducting polymers,Eletrochemical materials science division,Central Electrochemical \\ research Institute, Karikudi-630006, India \\ ${ }^{c}$ PSG College of Technology Peelamedu, Coimbatore 641 004, India
}

\begin{abstract}
The corrosion inhibitive action of flower extracts of Magnolia champaca flower on mild steel corrosion in $0.5 \mathrm{M} \mathrm{H}_{2} \mathrm{SO}_{4}$ solution was studied using weight loss method, potentiodynamic polarization and EIS measurements. The results obtained indicate that the extracts functioned as good inhibitors in $0.5 \mathrm{M} \mathrm{H}_{2} \mathrm{SO}_{4}$ solution. Inhibition efficiency was found to increase with extract concentration. The adsorption of constituents in the plant extract on the surface of the metal is proposed for the inhibition behavior.
\end{abstract}

Key words: - Inhibitor, Mass loss, Impedance, Polarization, Magnolia champaca

\section{INTRODUCTION}

Inhibitors are frequently used for controlling corrosion of metals and alloys in acidic media for removing scales and rusts in metal finishing industries, cleaning of boilers and heat exchangers. Use of inhibitors is one of the most practical methods for protection against corrosion especially in acid solutions to prevent unexpected metal dissolution and acid consumption [1,2]. The known hazardous effect of most synthetic corrosion inhibitors have motivated scientists to use naturally occurring products as corrosion inhibitors as they are inexpensive, readily available and renewable sources of materials, environmentally friendly and ecologically acceptable [3,4]. Up till now saps of certain plant leaves such as Murraya koenigii, Embilica officianilis, Terminalia chebula, Terminalia belivia, Sapindus trifolianus , Accacia conicianna „Swertia angustifolia. Eugenia jambolans, Pongamia glabra, Annona squamosa ,Accacia Arabica ,Occimum viridis, Telferia occidentalis, Carica papaya, Azadirachta indica Vernonia amydalina, Nypa fructicans wurmb ,Ricimus communis coriander, hibiscus, Eucalyptus, anis, black cumin and garden cress have been studied for the corrosion inhibition of mild steel in acid media [5-11].Some of the fruits such as Tobacco, castor oil fruits, acacia gum and lignin along with .Papaia, Poinciana pulcherrima, Cassia occidentalis and Datura stramonmium have also been used as efficient corrosion inhibitor for steel [12-16].The anticorrosion activity of onion, garlic and bitter gourd for mild steel in acid media showed good results studied. Oil

extracts of Ginger, jojoba, eugenol, acetyl-eugenol, artemisia oil and Mentha pulegium are used for corrosion J. Mater. Environ. Sci. 1 (3) (2010) 162-174 Singh et al. 164 inhibition of steel in acid media [17, 18].Saps of certain plants is very useful corrosion inhibitors. Calotropis procera, Azydracta indica and Auforpio turkiale sap are useful as acid corrosion inhibitors. Quinine has been studied for its

anticorrosive effect of carbon steel in $1 \mathrm{M} \mathrm{HCl}$. The inhibition effect of Zenthoxylum alatum extract on the corrosion of mild steel in aqueous Orthophosphonic acid was investigated. [19-21].In continuation of our work on development of green corrosion inhibitors [22-23], the present study investigates the inhibiting effect of Magnolia champaca flower extract on the corrosion of mild steel in $0.5 \mathrm{M} \mathrm{H}_{2} \mathrm{SO}_{4}$ solution by weight loss, potentiodynamic polarization and electrochemical impedance spectroscopy (EIS) methods.

\section{MATERIAL AND METHODS}

2.1 Preparation of Magnolia champaca flower extract:

An aqueous extract of Soundar roja flower plant leaves was prepared by grinding $5 \mathrm{~g}$ of plant flower, with distilled water, filtering the suspending impurities, and making up to $100 \mathrm{ml}$. The extract was used as corrosion inhibitor in the present study.

\section{2 preparation of specimens}

Carbon steel specimens $(0.022 \% \mathrm{~S}, 0.038 \% \mathrm{Mn}, 0.027 \% \mathrm{P}, 0.086 \mathrm{C})$ of dimension $1.0 \mathrm{~cm} * 4.0 \mathrm{~cm} * 0.2 \mathrm{~cm}$ were polished to a mirror finished with the emery sheets of various grades and degreased with trichloroethylene. 


\subsection{Weight loss method.}

Carbon steel specimens in triplicate were immersed in $100 \mathrm{~mL}$ of the inhibited and uninhibited $0.5 \mathrm{M}$ $\mathrm{H}_{2} \mathrm{SO}_{4}$ solutions in the presence and absence of TBAB for two hours. The weight of each specimen before and after immersion was determined using shimadzu balance, model Ay 62.The inhibition efficiency (IE) was then calculated using the expression;

$\mathrm{I}^{\mathrm{IE} \%=\left(\frac{\mathrm{W}_{1}-\underline{\mathrm{W}}_{2}}{\mathrm{~W}_{1}}\right) \times 100}$

Where $\mathrm{W}_{1}$ and $\mathrm{W}_{2}$ are the corrosion rates in the absence and presence of the inhibitor, respectively.

\subsection{Electrochemical impedance measurements Impedance measurements}

The impedance measurements were perfomed using a computer -controlled potentiostat (model Solartron SI-1260) and the data were analysed using gain phase analyser electrochemical interface (Solartron SI-1287). A three electrode set up was employed with Pt foil as the auxiliary electrode and a saturated calomel electrode as the reference electrode. The Teflon coated mild steel rod, with the surface prepared as described in the weight loss experimental method, served as the working electrode. The measurements were carried out in the frequency range $10^{6}-10^{-2} \mathrm{~Hz}$ at the open circuit potential by superimposing sinusoidal AC signal of small amplitude, $10 \mathrm{mV}$, after an immersion period of $30 \mathrm{~min}$ in the corrosive media. The double layer capacitance $\left(\mathrm{C}_{\mathrm{dl}}\right)$ and charge transfer resistance $\left(\mathrm{R}_{\mathrm{ct}}\right)$ were obtained from the impedance plots as described elsewhere ${ }^{24}$. Because $R_{c t}$ is inversely proportional to corrosion current density, it was used to determine the inhibition efficiency (IE\%) using the relationship;

$$
\mathrm{IE} \%=\frac{\text { Rct }-\mathbf{R}^{\circ} \mathbf{c t}}{\text { Rct }} \times 100
$$

Where $R_{c t}$ and $R_{c t}^{0}$ are the charge transfer resistance values in the inhibited and uninhibited solutions respectively.

\subsection{Polarization measurements}

The potentiodynamic polarization curves were recorded using the same cell setup employed for the impedance measurements. The potentials were swept at the rate of $1.66 \mathrm{mV} / \mathrm{s}$, primarily from a more negative potential than $\mathrm{E}_{\text {ocp }}$ to a more positive potential than $\mathrm{E}_{\text {ocp }}$ through $\mathrm{E}_{\text {corr }}$. The inhibition efficiencies were calculated using the relationship ${ }^{25}$;

$$
\mathrm{IE} \%=\frac{\mathrm{I}^{\circ} \text { corr }-\mathrm{Icorr}}{\mathrm{I}^{\circ} \text { corr }} \times 100
$$

Where $I^{0}$ corr and $I_{\text {corr }}$ are the corrosion current densities in the absence and in the presence of inhibitor, respectively

\subsection{Analysis of results of mass loss method}

\section{RESULTS AND DISCUSSION}

The corrosion rates and inhibition efficiency values, calculated using weight loss data, for various concentrations of Magnolia champaca extract in the presence and absence of TBAB the corrosion of carbon steel in $0.5 \mathrm{M} \mathrm{H}_{2} \mathrm{SO}_{4}$ solution are presented in Table.1. It is apparent that the inhibition efficiency increased with the increase in inhibitor concentration in the presence and absence of TBAB. This behavior can be explained based on the strong interaction of the inhibitor molecule with the metal surface resulting in adsorption. The extent of adsorption increases with the increase in concentration of the inhibitor leading to increased inhibition efficiency. The maximum inhibition efficiency was observed at an inhibitor concentration of $100 \mathrm{ppm}$. Generally, inhibitor molecules suppress the metal dissolution by forming a protective film adsorbed to the metal surface and separating it from the corrosion medium. The corrosion suppressing ability of the inhibitor molecule originates from the tendency to form either strong or weak chemical bonds with Fe atoms using the lone pair of electrons present on the $\mathrm{O}$ and $\pi$ electrons in benzene ring. It is also seen from table. 1 that the leaf extract of Soundar roja flower at $2 \mathrm{~mL}$ and $10 \mathrm{~mL}$ concentrations shows $68.25 \%$ and $81.74 \%$ inhibition efficiencies respectively, Then the values increased to $93.65 \%$ after adding $25 \mathrm{ppm}$ of TBAB solution in $0.5 \mathrm{M} \mathrm{H}_{2} \mathrm{SO}_{4}$ solutions containing $10 \mathrm{~mL}$ of plant extract respectively. This showed a good synergistic effect between sounder roja leaves and TBAB. 
Table1.Corrosion rate (CR) of mild steel in $0.5 \mathrm{M} \mathrm{H}_{2} \mathrm{SO}_{4}$ solutions the absence and presence of inhibitor and the inhibition efficiency (IE) obtained by mass loss method.

\begin{tabular}{|c|c|c|}
\hline Inhibitor concentration (mL) & \multicolumn{2}{|c|}{ TBAB (0) ppm } \\
\cline { 2 - 3 } & CR (mdd) & IE \\
\hline 0 & 126 & 68.25 \\
\hline 2 & 40 & 76.19 \\
\hline 4 & 30 & 79.36 \\
\hline 6 & 26 & 80.95 \\
\hline 8 & 24 & 81.74 \\
\hline 10 & 23 & \% \\
\hline
\end{tabular}

3.2 INFLUENCE OF TBAB ON THE INHIBITION EFFICIENCY OF FLOWER EXTRACTS

\begin{tabular}{|l|c|c|}
\hline Inhibitor concentration (mL) & \multicolumn{2}{|c|}{ TBAB (25) ppm } \\
\cline { 2 - 3 } & CR (mdd) & IE \% \\
\hline 10 & 8 & 93.65 \\
\hline
\end{tabular}

\subsection{Electrochemical impedance spectroscopic measurements (EIS)}

Impedance spectra obtained for corrosion of mild steel in $0.5 \mathrm{M} \mathrm{H}_{2} \mathrm{SO}_{4}$ contains two semicircles in which the second one represents the interaction of metal surface with the corrosive environment. The first semicircle represents the nature of the corrosive media. Since the conductivity of the corrosive medium is very low, this also behaves like a leaky capacitor. The CR-CR model best describes this situation. The second semicircle in the impedance plots contain depressed semicircles with the centre below the real axis. The size of the semicircle increases with the inhibitor concentration, indicating the charge transfer process as the main controlling factor of the corrosion of mild steel. It is apparent from the plots that the impedance of the inhibited solution has increased with the increase in the concentration of the inhibitor. The experimental results of EIS measurements for the corrosion of mild steel in $0.5 \mathrm{M} \mathrm{H}_{2} \mathrm{SO}_{4}$ in the absence and presence of inhibitor are given in Table 3. Said that sum of charge transfer resistance $\left(R_{c t}\right)$ and adsorption resistance ( $\left.R a d\right)$ is equivalent to polarization resistance $(\mathrm{Rp})$.

Table 3. Impedance parameters obtained from electrochemical impedance studies.

\begin{tabular}{|c|c|c|c|}
\hline Inhibitor concentration $\mathrm{mL}$ & Ret Ohm cm $^{2}$ & $\mathbf{C}_{\mathrm{dl}} \boldsymbol{\mu F}$ & IE\% \\
\hline 0 & 17.2 & 92.57 & - \\
\hline $\mathbf{1 0}$ & 101 & 42.78 & 83.0 \\
\hline 10+ 25ppm(TBAB) & 238 & 6.69 & 92.8 \\
\hline
\end{tabular}

\subsection{Potentiodynamic Polarization studies :}

Fig 2. Potentiodynamic polarization curves of mild steel immersed in $0.5 \mathrm{M} \mathrm{H}_{2} \mathrm{SO}_{4}$ solution in the absence and presence of inhibitors

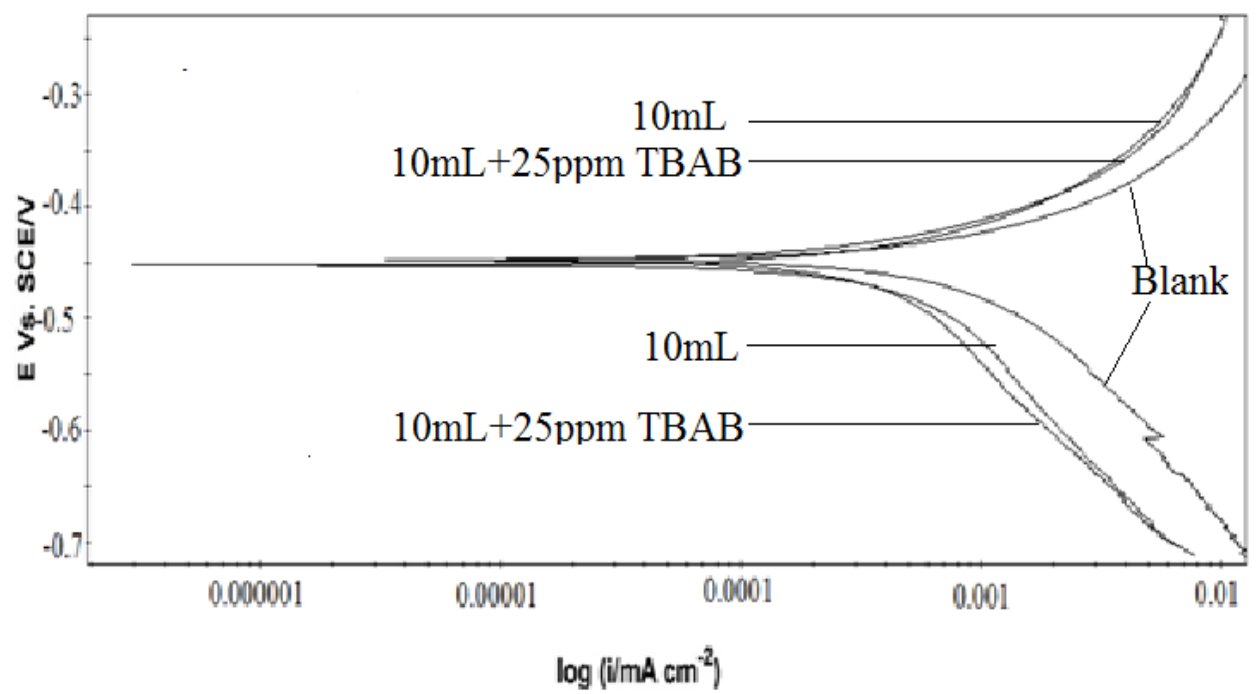


Table 4. Corrosion parameters in the presence and absence of inhibitor obtained from polarization measurements.

\begin{tabular}{|l|l|l|l|l|l|}
\hline Inhibitor concentration $\mathrm{mL}$ & $-\mathrm{E}_{\mathrm{corr}}(\mathrm{mV})$ & $\beta_{\mathrm{c}}(\mathrm{mV} /)$ & $\beta_{\mathrm{a}}(\mathrm{mV})$ & $\mathrm{I}_{\text {corr }} \times 10 * 6 \mu \mathrm{A}$ & $\mathrm{IE} \%$ \\
\hline 0 & 447 & 181 & 85 & 1.35 & \\
\hline 10 & 450 & 203 & 102 & 0.243 & 82.0 \\
\hline $10+25 \mathrm{ppmTBAB}$ & 453 & 201 & 105 & 0.105 & 92.2 \\
\hline
\end{tabular}

The polarization curves obtained for the corrosion of mild steel in the inhibited (100 ppm) and uninhibited $0.5 \mathrm{M} \mathrm{H} \mathrm{H}_{2} \mathrm{SO}_{4}$ solutions in the absence and presence of KI are shown in Fig.2. Electrochemical parameters such as corrosion potential $\left(\mathrm{E}_{\text {corr }}\right)$, corrosion current density $\left(\mathrm{I}_{\text {corr }}\right)$, cathodic and anodic tafel slopes $\left(\beta_{\mathrm{c}}\right.$ and $\left.\beta_{\mathrm{a}}\right)$ and percentage inhibition efficiency according to polarization studies are listed in table 4 . Here $\mathrm{I}_{\text {corr }}$ decreased with increasing inhibitor concentration. From the figures, it can be interpreted that the addition of this inhibitor to corrosive media changes the anodic and cathodic tafel slopes. The changes in slopes showed the influence of the inhibitor both in the cathodic and anodic reactions. However, the influence is more pronounced in the cathodic polarization plots compared to that in the anodic polarization plots. Even though $\beta_{\mathrm{c}}$ and $\beta_{\mathrm{a}}$ values (table.3) change with an increase in inhibitor concentrations, a high $\beta_{\mathrm{c}}$ value indicates that the cathodic reaction is retarded to a higher extent than the anodic reaction ${ }^{26}$.

From Fig. 2 it is also clear that the addition of the inhibitor shifts the cathodic curves to a greater extent toward the lower current density when compared to the anodic curves. The $\mathrm{E}_{\text {corr }}$ value is also shifted to the more negative side with an increase in the inhibitor concentration. These shifts can be attributed to the decrease in the rate of the hydrogen evolution reaction on the mild steel surface caused by the adsorption of the inhibitor molecule to the metal surface ${ }^{27}$. It has been reported that a compound can be classified as an anodic and cathodic type inhibitor on the basis of shift of $E_{\text {corr }}$ value. If displacement of $E_{\text {corr }}$ value is greater than $85 \mathrm{mv}$, towards anode or cathode with reference to the blank, then an inhibitor is categorized as either anodic or cathodic type inhibitor otherwise inhibitor is treated as mixed type ${ }^{28,29}$. In our study, maximum displacement in $\mathrm{E}_{\text {corr }}$ value was around $6 \mathrm{mV}$, indicating the inhibitor is a mixed type and more anodic nature and does not alter the reaction mechanism. The inhibition effect has occurred due to simple blocking of the active sites, thereby reducing available surface area of the corroding metal ${ }^{30,31}$. The increase in inhibitor efficiency of inhibited $(10 \mathrm{~mL}) 0.5 \mathrm{M}$ $\mathrm{H}_{2} \mathrm{SO}_{4}$ solution for the corrosion of mild steel after adding $25 \mathrm{ppm}$ TBAB shows synergism between inhibitor molecules and TBAB.

\section{CONCLUSIONS}

Results obtained from both electrochemical methods showed that the Magnolia champaca flower acts as an inhibitor for corrosion of steel in $0.5 \mathrm{M} \mathrm{H}_{2} \mathrm{SO}_{4}$ media. Corrosion inhibition action of Magnolia champaca flower increased as its concentra tion increases. Inhibition of steel in $0.5 \mathrm{M} \mathrm{H}_{2} \mathrm{SO}_{4}$ solution by Magnolia champaca flower is attributed to adsorption of the phytochemical compounds in this extract.

\section{ACKNOWLEDGEMENTS}

The authors generously acknowledge the support by Dr.R.SomasundaramM.D., Dr.R.Arul M.Sc.,Ph.D., Dr.S.Vedanayaki M.Sc.,Ph.D., President ,Principal and head of the department chemistry respectively of kandaswami Kandar's college,P.Velur for providing necessary chemical and lab facilities to carry out chemical studies.

\section{REFERENCES}

[1] Ashassi-Sorkhabi, H., Seifzade, D., Hosseini, M.G. Corros. Sci. 50 (2008) 3363.

[2] Satapathy, A.K., Gunasekaran, G., Sahoo, S.C., Kumar, A., Rodrigues, P.V. Corros. Sci. 51 (2009) 2848.

[3] Abdel-Gaber, A.M., Abd-El-Nabey, B.A., Saadawy, M. Corros. Sci. 51 (2009)1038-1042.

[4] Raja, P.B., Sethuraman, M.G. Mater. Lett. 62 (2008) 113.

[5] Noor, E.A. J. Engg. Appl. Sci. 3 (2008) 23.

[6] Buchweishaija, J., Mhinzi, G.S. Port. Electrochim. Acta 26 (2008) 257.

[7] Oguzie, E.E. Corros. Sci. 50 (2008) 2993.

[8] Okafor, P.C., Ikpi, M.E., Uwaha, I.E., Ebenso, E.E., Ekpe, U.J., Umoren, S.A. Corros. Sci. 50 (2008) 2310.

[9] Valek, L., Martinez, S. Mater. Lett. 61 (2007) 148.

[10] Oguzie, E.E. Corros. Sci. 50 (2008) 2993.

[11] Singh, Ambrish, Ahamad, I., Singh, Vinod Kumar, Quraishi, M.A. (2010) J.S.E.L. 2010 JSEL-D-1000143R2.

[12] Noor, E.A. J. Appl. Electrochem. 39 (2009) 1465. 
[13] De Souza, F.S., Spinelli, A. Corros. Sci. 51 (2009) 642.

[14] Raja, P.B., Sethuraman, M.G. Mater. Lett. 62 (2008) 1602.

[15] El-Etre, A.Y. Corros. Sci. 45 (2003) 2485.

[16] Badiea, A.M., Mohana, K.N. J. Mater. Eng. Perform. 18 (2009) 1264.

[17] Chauhan, L.R., Gunasekaran, G. Corros. Sci. 49 (2007) 1143.

[18] El-Etre, A.Y., Abdallah, M., El-Tantawy, Z.E. Corros. Sci. 47 (2005) 385.

[19] Orubite, K.O., Oforka, N.C. Mater. Lett. 58 (2004) 1768.

[20] Evic Grassino, A.N., Grabaric, Z., Pezzani, A., Fasanaro, G., Voi, A.L. Food Chem. Toxicol 47 (2009) 1556.

[21] Torres-Acosta, A.A. J. Appl. Electrochem. 37 (2007) 835.

[22] Quraishi, M.A., Singh, Ambrish, Singh, Vinod Kumar, Yadav, Dileep Kumar, Singh, Ashish Kumar Mater. Chem. Phy. 122 (2010) 114.

[23] Quraishi, M.A., Yadav, Dileep Kumar, Ahamad Ishtiaque The Open Corrosion Journal 2 (2009) 56.

[24] Ashassi-Sorkhabi.H,.Shaabani.B,Seifzadeh.D, Electrochim. Acta, $2005,50,3446$.

[25] Shahin.M, Bilgie.S, Yilmaz.H, Appl. Surf. Sci.2003,195, 1.

[26] Silverman D. C., "Practical Corrosion Prediction Using Electrochemical Techniques", ch. 68 in Uhlig's Corrosion Handbook, $2^{\text {nd }}$ edition (Revie,.R.W, ed.), The Electrochemical Society, 2000.

[27] Prabhu., T.V. Venkatesha, A.V. Shanbhag. Praveen. B.M, Kulkarni. G.M,.Kalkhambkar R.G, Mater. Chem. Phys. 2008,108, 283

[28] Sanghvi. R.A, M.J., et al., Bull. Electrochem.1999, 13, 358.

[29] Felicia Rajammal Selvarani, S.Santhanalakshmi, J. Wilson sahayaraja, A. John Amalraj,and Susai Rajendran, Bull. Electrochemistry.2004, 20, 561-565.

[30] Susai RajendranS. Mary Reenkala, Noreen Anthony and Ramaraj,R. Corros Sci,2002, 44, 2243-2252.

[31] Scully. J. R., "Polarization Resistance Method for Determination of Instantaneous Corrosion Rates", Corrosion, Vol.2000,56, p. 199. 